\title{
Temperature Characteristics Analysis of Braking Resistor for High Speed Train
}

\author{
Dae-Dong LEE ${ }^{1}$, Jae-Myung SHIM ${ }^{2}$, Dong-Seok HYUN ${ }^{1}$ \\ ${ }^{1}$ Department of Electrical Engineering, Hanyang University, \\ 17, Haengdang-dong, Seongdong-gu, Seoul, 133-791, Republic of Korea, \\ ldd77@hanbat.ac.kr, dshyun@hanyang.ac.kr; (Corresponding author) \\ 2 Department of Electrical Engineering, Hanbat National University, \\ San 16-1, Duckmyoung-dong, Yeseong-gu, Daejeon, 305-719, Republic of Korea, \\ jmshim@hanbat.ac.kr
}

\begin{abstract}
Dynamic braking, which is frequently used in high speed trains, is a function and device that provides braking force using the electricity that is generated from a traction electric motor, and also dissipates heat from the braking resistor that converts the current from the traction electric motor into heat. The heat from the braking resistor, which is located in the motor block of a high speed train, damages the resistor wires and induces cracks in the insulators that affect the dynamic choppers, traction inverters, and electric motors during dynamic braking, and makes it difficult to control driving during acceleration or deceleration. In this study, the motor block braking resistor, which was recently suggested to compensate for these problems, was designed, and experiments were performed on heat analysis simulation and temperature increase. Further field tests were performed to verify the advantages of the motor block braking resistor.
\end{abstract}

Keywords: Braking resistor, field test, high speed train, motor block, temperature increase test, total heat flux

\section{Introduction}

Technologies on railway vehicles have been enhancing the overall capabilities to design and operate mass transportation systems such as general trains, subway trains, and light rail transit. Korea Train eXpress(KTX), which was recently introduced and operated, has 20 cars per train and currently has 46 trains running, 34 of which are domestically manufactured and the others, imported [1].

The power source of the train is $25 \mathrm{kV}$, singlephase, $60 \mathrm{~Hz}$ AC, and its traction and braking forces are 13,560 kW and $300 \mathrm{KN}$, respectively. Its braking methods include regeneration braking, dynamic braking, and air braking. The motor block resistor, which is used in regeneration and dynamic braking, is called the braking resistor. The motor block is a key element of the performance enhancement and stability of a train. The electric braking circuit of a high speed train normally secures the braking force by controlling the braking chopper according to the amount of regenerated energy. In case of emergency braking or a dead section, however, when the current input to the motor block is above the limit, the circuit activates the dynamic braking, in which the excessive current is discharged as a form of heat through the braking resistor. The heat from the braking resistor, however, damages the resistor wires and induces cracks in the insulators that affect the dynamic choppers, inverters, and traction electric motors during dynamic braking, and make it difficult to control driving during acceleration or deceleration.

In this study, the motor block braking resistor, which was recently suggested to compensate for these problems, was designed, and heat analysis simulation and temperature increase experiments were performed. The advantages of the motor block braking resistor were verified through further field tests.

\section{Motor Block Braking Resistor}

\subsection{Structure of the propulsion system of a high speed train}

The parts of the motor block of a high speed train are shown in Figure 1. The motor block has two thyristor converters, one smoothing reactor, two inverters, two three-phase synchronous motors, one chopper, and two Power Factor Correction (PFC) circuits for power factor control and harmonic wave reduction [2].

The main transformer converts the $25 \mathrm{kV}$ cable voltage into $1,800 \mathrm{~V}$, and the two single-phase bridge rectifiers that are serially connected and make up a thyristor perform variable rectification of the transformer's second winding voltage according to the switching degree. The current of the rectified DC source is smoothened by the smoothing reactor and flows into the two traction electric motors, which are composed of two $1,130 \mathrm{~kW}$ threephase synchronous motors and two three-phase 


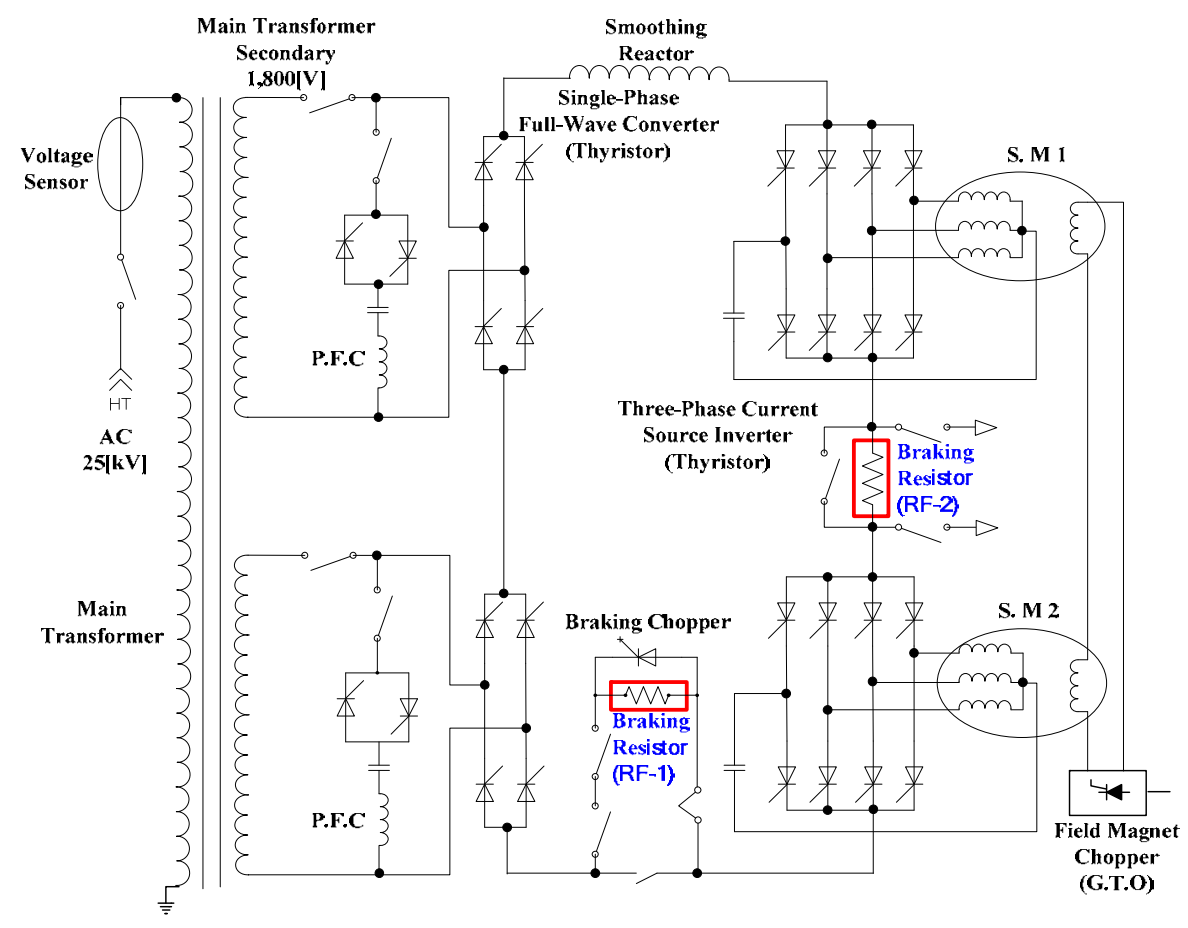

Figure 1. Circuit of the propulsion control system of a high speed train

current-type inverters that control acceleration or deceleration and regeneration [3-5].

The inverter has a forced commutation mode and a natural commutation mode. In the forced commutation mode, the current is rectified by the capacitor and thyristor, and in the natural commutation mode, by the inter-phase voltage generated by the counter-electromotive force of a synchronous motor [6].

\subsection{Structure and role of the motor block}

The motor block braking resistor is installed at the direct-current link of the input unit of the high speed train's propulsion control system, as shown in Figure 1 [7].

The braking resistor is controlled by the separately excited inverter operation of a converter and composed of two circuits: one for securing the electric braking force in normal operations by controlling the braking chopper according to the amount of the regenerated energy, and the other for dissipating the generated electric energy from the synchronous motor in the case of a dead section, a cable voltage of over $25 \mathrm{kV}$, and a transformer malfunction.

One of the roles of the braking resistor is to stabilize the direct end voltage through a chopper device and to perform dynamic braking in dead sections. As a result of the deceleration of the motor.

The traction motor of the currently running high speed train uses 12 synchronous motors with a $1,130 \mathrm{~kW}$ output per formation. The synchronous motor is more complex than the induction motor in terms of structure and repair/maintenance, but it is by far simpler in structure and repair/maintenance than the direct current motor and has the characteristics of the direct current series motor in the early stage, which requires a great maneuvering torque. Moreover, in the high speed domain of more than $120 \mathrm{~km} / \mathrm{h}$, commutation is automatically done by a counter electromotive force. It thus has simple control characteristics, similar to those of the induction motor.

Each power driving car has two motor blocks, and each power driving passenger car has one. Thus, one formation has a total of six motor blocks. The main transformer of power-driving cars on both sides supplies power to the three motor blocks on the same side. Each motor block controls two traction motors and has power supply-related devices.

The phase compensation circuit (PFC) improves the high-frequency power current induced by the second coil of the main transformer and by the phase difference of the current and voltage, and supplies the waveform 
close to the sine wave by filtering the third 60 $\mathrm{Hz}$ high frequency current of $180 \mathrm{~Hz}$.

As for the converter, the two converters connected in series to each motor block consist of a combination of thyristors and reactors and rectify AC $1,800 \mathrm{~V}$ of the main transformer's second coil and at the same time adjust the traction current (output current) supplied to the inverter.

The current-type inverter makes three-phase alternating-current power by supplying the traction current supplied to the converter to the stator coil of the traction motor. The inverter has two control methods according to the speed: at the low speed of $120 \mathrm{~km} / \mathrm{h}$, it controls the thyristor in the forced changeover system of arc extinction using the transfer circuit, and at the speed of over 120 $\mathrm{km} / \mathrm{h}$, it controls the thyristor of the inverter in the natural change-over system of automatic arc extinction using the counter electromotive force of the traction motor.

Two motor blocks are connected in series to the inverter, and one traction motor is connected to each inverter. The inverter in the regenerative braking mode plays the role of a converter, which converts the alternating current generated from the traction motor to a direct current.

Each motor block has one motor block blower inverter, which supplies three-phase alternating-current power to one motor block blower inverter cooling the power units, such as the dynamic braking resistor (RF-1), converter, and inverter. In the traction and regenerative braking mode, the motor block blower inverter receives DC $570 \mathrm{~V}$ coming from the auxiliary converter, but in the dynamic braking mode, it receives the voltage generated at both ends of the braking resistor (RF-2) located between the two traction inverters, as input power. In each motor block, there are three blower motors, which cool the motor block, induct air from below to above, and cool the braking resistor located above, and then discharge the air through the exhaust outlet on the roof the power-driving car.

In the regenerative braking mode, the chopper of the contraction motor works like a current generator, and the two inverters are controlled in the rectifier mode. This current is sent to the braking chopper connected to the braking resistor (RF-1), and the braking chopper passes this current with the greatest conduction rate. The traction converter is controlled to adjust the current coming from the inverter (rectifier), and this current is sent to the silicon bronze wire. The traction converter in this case plays the role of an inverter that converts direct current to alternating current. In the dynamic braking mode, the traction motor rotator receives power from the magnetized chopper acting through battery power.

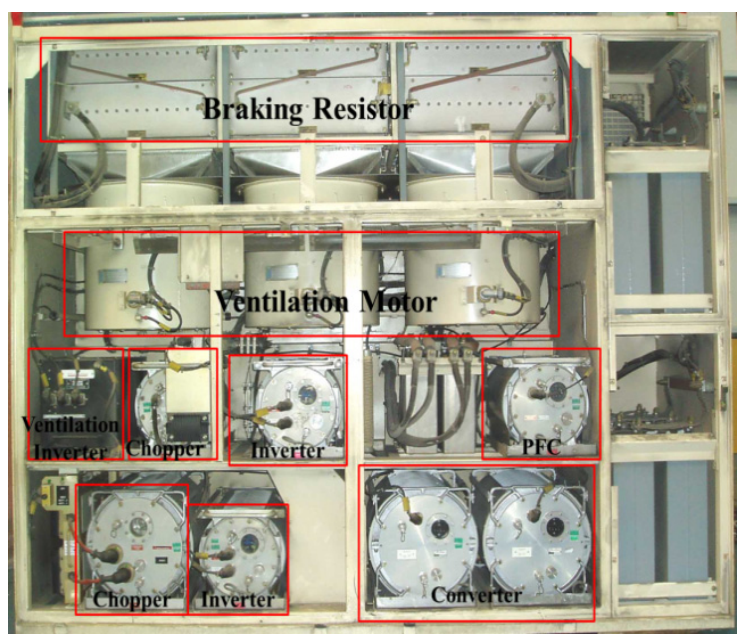

Figure 2. Structure of the motor block

The traction motor acts like a current generator and the two inverters are controlled as a rectifier. In this mode, the chopper makes the generated current flow towards the braking resistor (RF-1) with the least conduction.

As seen in Figure 1, the RF-1 braking resistor is used to dissipate electric energy under dynamic braking, and RF-2 is used to adjust the cooling fan voltage to cool the resistor and the inside of the motor block.

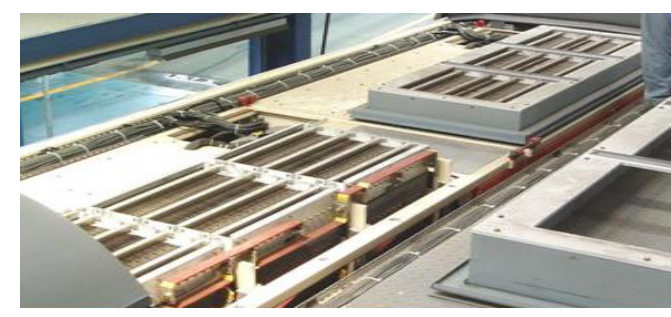

Figure 3. Fan hood of the braking resistor

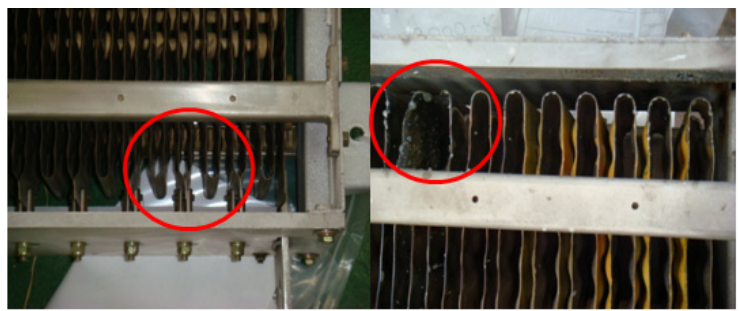

Figure 4. Damages to resistor wires 


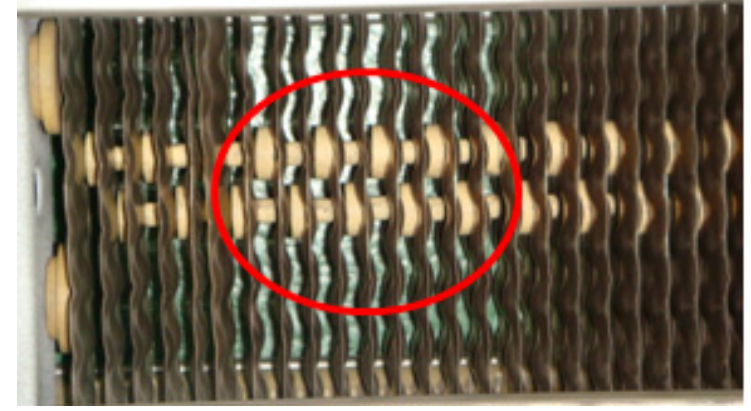

Figure 5. Cracks in the insulator

The braking resistor, installed in the upper position of the motor block structure as seen in Figure 2, is cooled by the fan motor located underneath, and the blown heat is discharged through high speed train hood, which is installed on top of the high speed train, as seen in Figure 3. The damages to the resistor wires due to the heat, as seen in Figure 4, and the cracks in the insulators, as seen in Figure 5, affect dynamic braking.

\subsection{Function of the braking resistor}

Braking is the action of stopping a running train by changing the kinetic energy proportional to the running speed of the train into other energies in a short time. Electric braking is divided into regenerative braking, which returns the kinetic energy of the rotator using a bidirectional switch, and dynamic braking, which consumes energy using braking resistors, etc. [8-9].

Regenerative braking can reduce energy loss by regenerating the energy into power, but the materials cost increases due to the use of bidirectional switches. In the case of the use of a unidirectional power conversion circuit, which rectifies AC power to DC power through a diode, as the rectification part cannot return the energy regenerated in the motor to $\mathrm{AC}$ power, the regenerated energy raises the DC link voltage. The most widely used method of consuming the energy built up in the DC link condenser is adding the braking resistor to the DC link condenser.

The power regenerated at the time of regenerative braking is first used as driving energy of a train driving in the same train-bus line, and when there is remaining regenerated energy, it is generally utilized after being changed into AC power in the inverter installed in the transformer, or is consumed through the resistor.

\subsection{Suggested braking resistor}

As conventional braking resistors experienced frequent damages to their wires with heat expansion, the recently suggested model reinforced the central part of the resistor, which is the most vulnerable part, with insulators to prevent damage.

In addition, considering the temperature increase due to the narrow interval between the resistors, instead of the previous structure of 28 resistors (28S), as seen in Figure 6 (a), the structure with 30 resistors (30S) was suggested, as seen in Figure 6 (b).

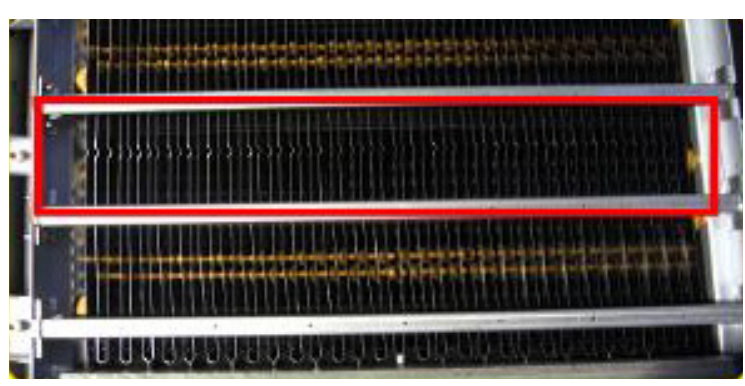

(a) Conventional model (28S)

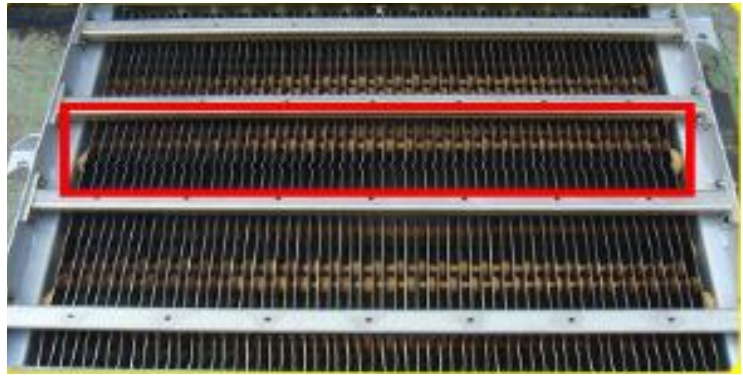

(b) Suggested model (30S)

Figure 6. Structure of braking resistors

The components of the conventional resistor wires were $\mathrm{Ni} / \mathrm{Cr} / \mathrm{Fe}$ with the proportions of $48 / 23 / 29 \%$ as seen in Table 1 , whereas the suggested model excludes the Fe component, which has a low melting point and uses the $\mathrm{Ni} / \mathrm{Cr}$ alloy at a ratio of $80 / 20 \%$ as seen in Table 2.

Table 1. Components of the conventional resistor wires

\begin{tabular}{|c|c|}
\hline Component & Result (\%) \\
\hline $\mathrm{Ni}$ & 45.5 \\
\hline $\mathrm{Cr}$ & 22.6 \\
\hline $\mathrm{C}$ & 0.04 \\
\hline $\mathrm{Si}$ & 1.89 \\
\hline $\mathrm{Mn}$ & 0.57 \\
\hline $\mathrm{Fe}$ & 28.8 \\
\hline Totals & 99.40 \\
\hline
\end{tabular}


Table 2. Components of the suggested resistor wires

\begin{tabular}{|c|c|}
\hline Component & Result (\%) \\
\hline $\mathrm{Ni}$ & 77.7 \\
\hline $\mathrm{Cr}$ & 20.2 \\
\hline $\mathrm{C}$ & 0.02 \\
\hline $\mathrm{Si}$ & 1.25 \\
\hline $\mathrm{Mn}$ & 0.02 \\
\hline $\mathrm{Fe}$ & 0.41 \\
\hline Totals & 99.60 \\
\hline
\end{tabular}

In contrast to the existing braking resistor model, an insulator was added to the proposed braking resistor model to keep the resistor materials' space constant, to address the disadvantage of the weakening of the mechanical structure at the time of thermal expansion.

The proposed braking resistor (RF-1) model has a structure in which six $0.55 \Omega$ resistors are connected in series, with a combined resistance of $3.3 \Omega$ as seen in Figure 7 and braking resistor (RF-2) model has a structure in which six $0.54 \Omega$ resistors are connected in series and parallel, with a combined resistance of $0.81 \Omega$ as seen in Figure 8. The braking resistor's Assembly is shown in Figure 9.

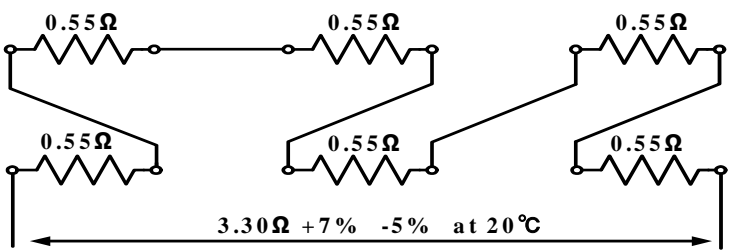

Figure 7. Structure of proposed braking resistor (RF-1)

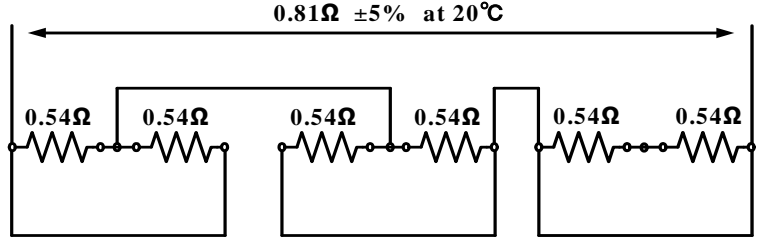

Figure 8. Structure of proposed braking resistor (RF-2)

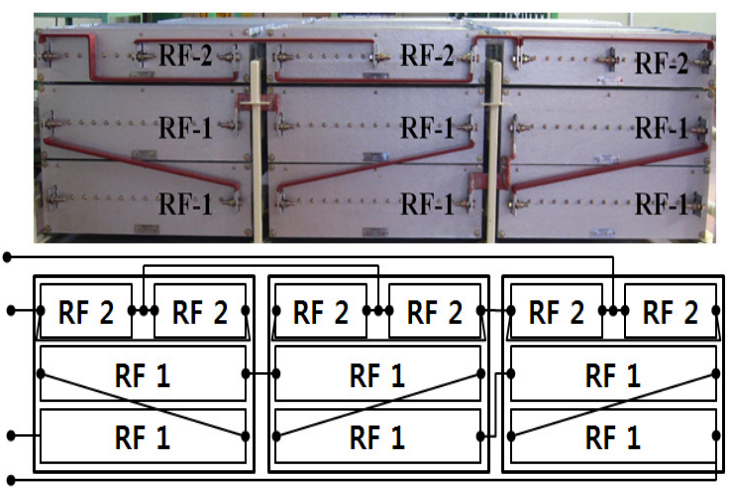

Figure 9. Braking resistor’s assembly

\section{Simulation Results and Analysis}

\subsection{Calculation of the increase in the temperature of a braking resistor}

Temperature increases in the braking resistors were calculated for both the conventional and suggested models during dynamic braking to consider the temperature increase due to the narrow intervals of the resistors.

The braking resistor had six units of resistor wires that were serially connected with a resistance of $0.55 \Omega$ per unit and a combined resistance of $3.3 \Omega$. The operating peak current (IP) under the combined resistance (RC) of 3.3 $\Omega$ and the operating voltage of $2,850 \mathrm{~V}$ was calculated as shown in equation (1). The amount of heat (Qcal) generated in the unit resistor with a resistance of $0.55 \Omega$ for one second was calculated using equation (2), as follows:

$\mathrm{Ip}=\mathrm{V} / \mathrm{R}_{\mathrm{C}}$

$\mathrm{Q}_{\text {cal }}=0.24 \mathrm{I}^{2} \mathrm{RT}$

Where in the specific heat (C) of the components of the resistor wire were 0.2079 $\mathrm{cal} / \mathrm{g}^{\circ} \mathrm{C}$ for $\mathrm{Ni}, 0.1178 \mathrm{cal} / \mathrm{g}^{\circ} \mathrm{C}$ for $\mathrm{Cr}$, and $0.1070 \mathrm{cal} / \mathrm{g}^{\circ} \mathrm{C}$ for $\mathrm{Fe}$.

The components of the conventional model (28S) were $\mathrm{Ni} / \mathrm{Cr} / \mathrm{Fe}$ with the proportions of $48 / 23 / 29 \%$. The total mass (M) was 20.23 $\mathrm{kg} / \mathrm{m}^{3}$, and the components of the suggested model (30S) were $\mathrm{Ni} / \mathrm{Cr}$ at a ratio of $80 / 20 \%$ and a total mass $(\mathrm{M})$ of $21.08 \mathrm{~kg} / \mathrm{m}^{3}$.

The composite specific heat (Cs) of the conventional model (28S) was $0.1579 \mathrm{cal} / \mathrm{g}^{\circ} \mathrm{C}$, and that of the suggested model (30S) was $0.1899 \mathrm{cal} / \mathrm{g}^{\circ} \mathrm{C}$. The temperature increase $(\mathrm{T})$ was calculated using equation (3).

Qcal $=$ CsMT

The calculation with equation (3) resulted in an increase in the final temperature of $30.82^{\circ} \mathrm{C} / \mathrm{s}$ for the conventional model (28S) and $24.59^{\circ} \mathrm{C} / \mathrm{s}$ for the suggested model (30S). It was found that the temperature increase was $6.28{ }^{\circ} \mathrm{C} / \mathrm{s}$ slower in the suggested model than in the conventional model.

\subsection{Thermal energy distribution in a braking resistor}

The temperature increase in the conventional model, under the conditions of no cooling fan 
and an initial temperature of $11^{\circ} \mathrm{C}$, is shown in Table 3. That of the suggested model is shown in Table 4.

Considering the temperature increase conditions in Table 3 and Table 4, the simulation that was performed with ANSYS, thermal analysis software, resulted in a thermal energy distribution based on the location of the braking resistor for the conventional model, as seen in Figure 10 (a), and suggested model, as shown in Figure 10 (b). The seven thermal energy distributions by location are listed in Table 5. The measured thermal energy distribution was lower in the suggested model, which implies that the thermal characteristics of the suggested model are superior to those of the conventional model.

Table 3. Temperature increase in the conventional model (28S)

\begin{tabular}{|c|c|}
\hline Time (sec) & Temperature $\left({ }^{\circ} \mathbf{C}\right)$ \\
\hline 0 & 11 \\
\hline 2 & 72.64 \\
\hline 4 & 134.28 \\
\hline 6 & 195.92 \\
\hline 8 & 257.56 \\
\hline 10 & 319.20 \\
\hline
\end{tabular}

Table 4. Temperature increase in the suggested model (30S)

\begin{tabular}{|c|c|}
\hline Time (sec) & Temperature $\left({ }^{\circ} \mathbf{C}\right)$ \\
\hline 0 & 11 \\
\hline 2 & 60.18 \\
\hline 4 & 109.36 \\
\hline 6 & 158.54 \\
\hline 8 & 207.72 \\
\hline 10 & 256.90 \\
\hline
\end{tabular}

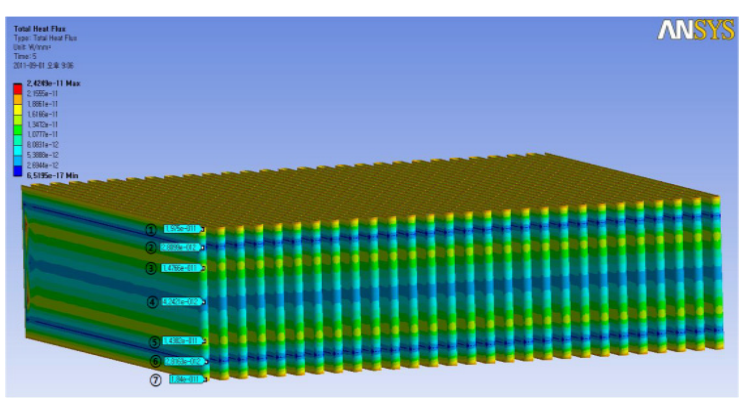

(a) Conventional model (28S)

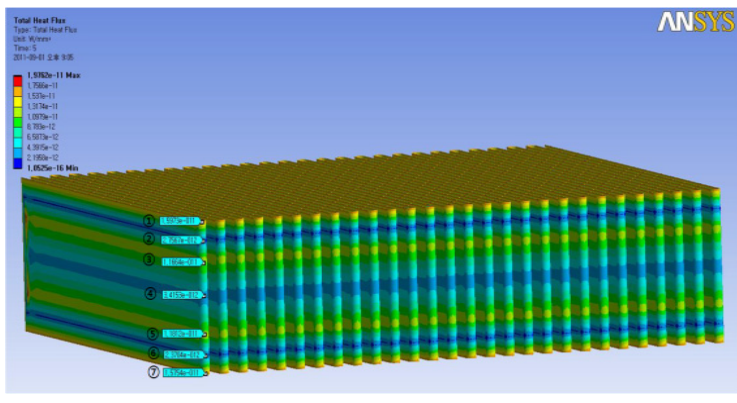

(b) suggested Model (30S)

Figure 10. Thermal energy distribution by location in braking resistors

Table 5. Thermal energy distribution by location

\begin{tabular}{|c|c|c|}
\hline Location & Conventional Model & Suggested Model \\
\hline$(1)$ & $1.9750 \mathrm{e}-11$ & $1.5973 \mathrm{e}-11$ \\
\hline$(2)$ & $2.8099 \mathrm{e}-12$ & $2.7567 \mathrm{e}-12$ \\
\hline$(3)$ & $1.4766 \mathrm{e}-11$ & $1.1664 \mathrm{e}-11$ \\
\hline 4 & $4.2421 \mathrm{e}-12$ & $3.4153 \mathrm{e}-12$ \\
\hline (5) & $1.4382 \mathrm{e}-11$ & $1.1812 \mathrm{e}-11$ \\
\hline 6 & $2.8163 \mathrm{e}-12$ & $2.3704 \mathrm{e}-12$ \\
\hline 7 & $1.8400 \mathrm{e}-11$ & $1.5754 \mathrm{e}-11$ \\
\hline
\end{tabular}

\section{Experiment Results and Analysis}

\subsection{Results of the temperature increase experiment}

Forced cooling of the braking resistor was performed with a cooling fan motor with a wind velocity of $2 \mathrm{~m} / \mathrm{sec}$ to keep the experiment conditions identical to those of the field, and the four spots at which the damages to the resistor wire were greatest in the field conditions with a surrounding temperature of approximately $11^{\circ} \mathrm{C}$ were selected for the temperature measurement, as shown in Figure 11.

The temperatures were measured with infrared thermometers because attached-type thermometers could not be used due to such harsh field conditions as high voltage, forced cooling, and limited spaces.

The results of the experiments on the conventional and suggested braking resistors under the same conditions are listed in Tables $6 \sim 9$. 
The average temperatures appear to be almost similar, but the smaller temperature increase was measured in the suggested model.

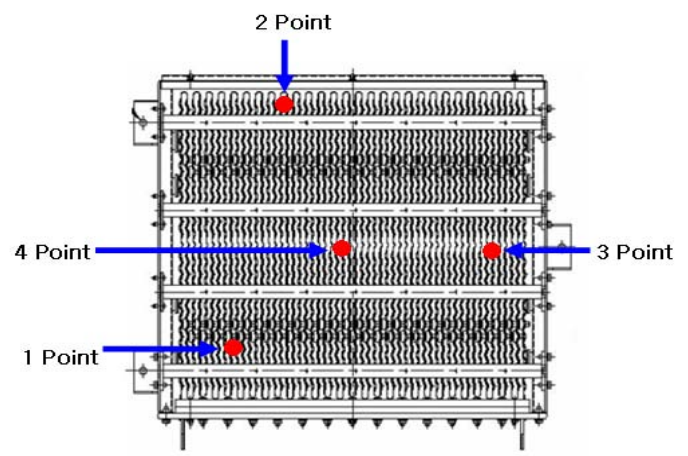

Figure 11. Temperature measurement points

Table 6. Results of the conventional model experiment (RF-1)

\begin{tabular}{|c|c|c|c|c|c|}
\hline \multirow{2}{*}{ Time (min.) } & \multicolumn{5}{|c|}{ Measurement Point in the Resistor $\left({ }^{\circ} \mathrm{C}\right)$} \\
\cline { 2 - 6 } & 1 & 2 & 3 & 4 & Ave. \\
\hline 15 & 245 & 172 & 216 & 209 & 211 \\
\hline 20 & 231 & 176 & 196 & 213 & 204 \\
\hline 25 & 241 & 170 & 212 & 208 & 208 \\
\hline 30 & 238 & 176 & 208 & 211 & 208 \\
\hline
\end{tabular}

Table 7. Results of the suggested model experiment (RF-1)

\begin{tabular}{|c|c|c|c|c|c|}
\hline \multirow{2}{*}{ Time (min.) } & \multicolumn{5}{|c|}{ Measurement Point in the Resistor $\left({ }^{\circ} \mathrm{C}\right)$} \\
\cline { 2 - 6 } & 1 & 2 & 3 & 4 & Ave. \\
\hline 15 & 245 & 191 & 175 & 215 & 207 \\
\hline 20 & 242 & 181 & 181 & 206 & 203 \\
\hline 25 & 244 & 184 & 180 & 212 & 205 \\
\hline 30 & 244 & 181 & 183 & 213 & 205 \\
\hline
\end{tabular}

Table 8. Results of the conventional model experiment (RF-2)

\begin{tabular}{|c|c|c|c|c|c|}
\hline \multirow{2}{*}{ Time (min.) } & \multicolumn{5}{|c|}{ Measurement Point in the Resistor $\left({ }^{\circ} \mathrm{C}\right)$} \\
\cline { 2 - 6 } & 1 & 2 & 3 & 4 & Ave. \\
\hline 15 & 171 & 134 & 145 & 143 & 148 \\
\hline 20 & 180 & 133 & 145 & 157 & 154 \\
\hline 25 & 183 & 135 & 150 & 144 & 153 \\
\hline 30 & 179 & 140 & 148 & 146 & 153 \\
\hline
\end{tabular}

Table 9. Results of the suggested model experiment (RF-2)

\begin{tabular}{|c|c|c|c|c|c|}
\hline \multirow{2}{*}{ Time (min.) } & \multicolumn{5}{|c|}{ Measurement Point in the Resistor $\left({ }^{\circ} \mathrm{C}\right)$} \\
\cline { 2 - 6 } & 1 & 2 & 3 & 4 & Ave. \\
\hline 15 & 159 & 132 & 147 & 141 & 145 \\
\hline 20 & 168 & 131 & 137 & 141 & 144 \\
\hline 25 & 160 & 130 & 139 & 143 & 143 \\
\hline 30 & 162 & 135 & 136 & 145 & 145 \\
\hline
\end{tabular}

\subsection{Field test results}

The wave forms of the currents during the regeneration braking and dynamic braking that were performed in the field conditions of speed $60 \mathrm{~km}$ for the conventional braking resistor and the suggested braking resistor were compared and analyzed.

The hicorder (HIOKI 8842, 16CH) and a clamp meter (HIOKI 3285, 2,000 A/1V) were used for the measurements, and the braking resistors of RF-1 and RF-2 in a motor block were selected as the measurement points.

Figure 12 shows the graph of the current wave form of the motor block grid resistor during the regeneration braking of an express train, and

The analysis of the current wave form, as seen in Figure 12 shows that regeneration braking at low speeds in the field test yields a small amount of currents that are not very different with conventional Model (42 A) and suggested Model (40 A).

Figure 13 shows the results of the dynamic braking. Figure 13 shows that the currents generated during dynamic braking in the field test were almost identical, and it is estimated that the two models have similar performance degrees with $120 \mathrm{~A}$.

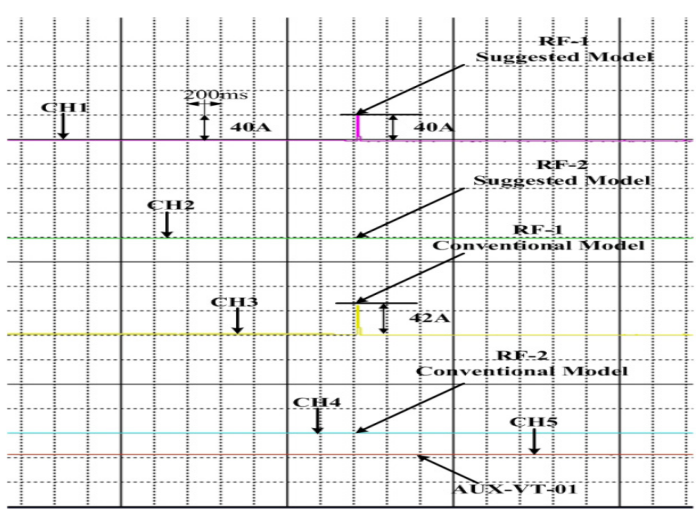

Figure 12. Current wave graph in a braking resistor during regeneration braking 


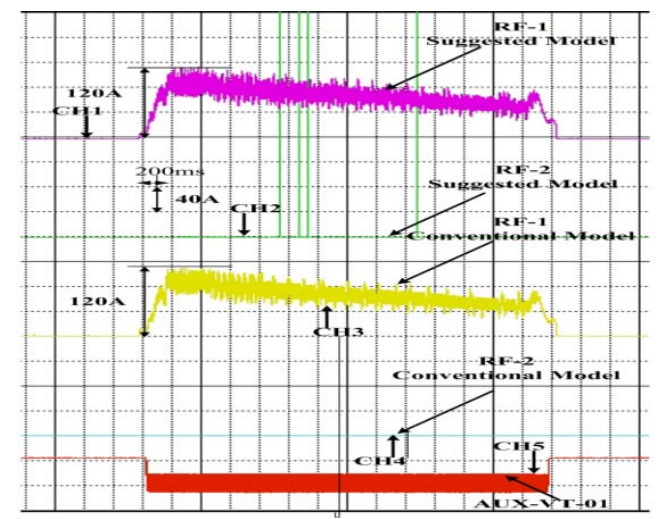

Figure 13. Current wave graph in a braking resistor during dynamic braking

\section{Conclusion}

In this study, a new suggested model for a motor block braking resistor was suggested to prevent damages to the resistor wires due to the thermal expansion during regeneration braking in a high speed train.

Resistors and insulators were added to the new braking resistor after considering the temperature increase in the conventional models due to the narrow resistors intervals, and the resistor temperature estimation through a component analysis confirmed that the temperature increase was less in the suggested model than in the conventional model.

Moreover, the outstanding performance of the suggested model was confirmed via the temperature increase experiment.

The current measurements in the field test also showed that the suggested model is superior to the conventional model during regeneration braking and its performance is similar to that of the conventional model during dynamic braking.

In addition, it was found that the new suggested braking resistor, which was suggested to maintain the proper temperatures, reduced the damages to the resistors and the cracks in the insulators during the operation of a high speed train, and thus helped secure the stability of the products and reduce the temperature inside a motor block. It is believed that the new suggested model will contribute to the best performance of the peripherals in a motor block, which include the inverter, chopper and converter, etc.

\section{REFERENCES}

1. LEE, W.-K., K.-B. PARK, A Study on Design of Propulsion and Control System for Korean High Speed Train, Spring Conference Proceedings on Korean Society for Railway, 2000, pp. 576-588.

2. LEE, E.-K., Y.-H. LEE, Y.-S. SONG, S.-B. KWON, Study Power Conversion Unit for Propulsion System of the Korea Train eXpress (KTX), Fall Conference Proceedings on Korean Society for Railway, 2009, pp. 2338-2345.

3. HAN, Y.-J., S.-W. KIM, K.-Y. CHOI, M.-S. CHO, S.-K. CHOI, J.-S. CHOI, J.-S. KIM, A Study on Traction Characteristics of KTX, Fall Conference Proceedings on Korean Society for Railway, 2003, pp. 175-180.

4. KIM, Y.-J., D.-S. KIM, H.-W. LEE, K.-D. SEO, N.-H. KIM, Main Power Conversion Device Development, Journal of Power Electronics, vol. 2, no. 4, 1997, pp. 21-28.

5. KNO, A.-S., E.-S. CHUNG, K.-C. HWANG, J.-M. CHOI, H.-J. RYOO, Y.-J. KIM, Development and Combined test of Traction system for the Korean High Speed Train, Fall Conference Proceedings on Korean Society for Railway, 2002, pp. 1013-1018.

6. BOSE, B. K., Power Electronics and Drives, 1986.

7. LEE, B.-S., Y.-S. BYUN, K.-S. BAIK, Power Conversion Unit for Propulsion System of the High Speed Train, Journal of Korean Society for Railway, vol. 2, no. 2, 1997, pp. 39-45.

8. CELENTANO, G., M. COVINO, E. PAGANO, Regenerative and Plugbraking Operation of Inverter-fed Asynchronous Motors, IEE Proceedings of Electric Power Applications, vol. 144, no. 6, 1997, pp. 453-455.

9. KIM, K.-W., Y.-M. SEO, S.-C. HONG, A Study on the Implementation of Inverter Systems for Regenerated Power Control, The Transactions of Korean Institute of Power Electronics, vol. 7, no. 2, 2002, pp. 205-213. 